\title{
Comparing the Effect of Dexamethasone, Normal Saline, and Metoclopramide on Prevention of Postoperative Nausea, Vomiting and Pain in Patient Undergoing Laparoscopic Cholecystectomy or Open Appendectomy: A Randomized Clinical Trial
}

\author{
Mohanad Y. Al-Radeef ${ }^{1}$, Sattar J. Abood ${ }^{2}$, Waleed K. Abdulsahib ${ }^{2 \star}$, Salah O. Hamad \\ ${ }^{1}$ Clinical Pharmacy Department, College of Pharmacy, Tikrit University, Iraq; ${ }^{2}$ Pharmacology Department, College of \\ Pharmacy, Al Farahidi University, Baghdad, Iraq; 3Surgery Department, Salah Aden General Hospital, Iraq
}

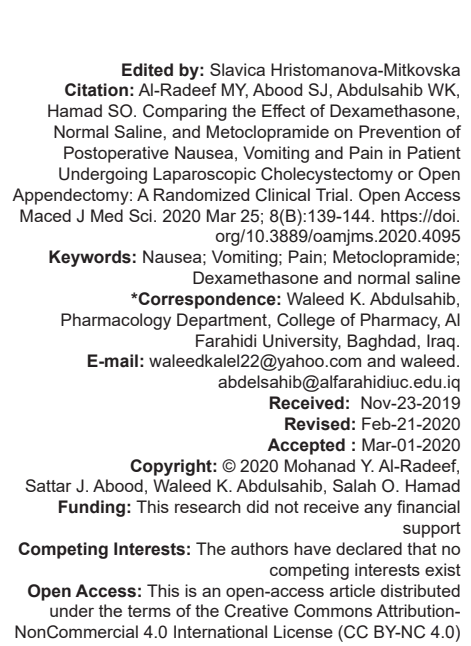

NonCommercial 4.0 International License (CC BY-NC 4.0)

\begin{abstract}
BACKGROUND: Post-operative nausea and vomiting (PONV) and pain are a common complications of adult patients undergoing anesthesia, but the incidence of these complications in patients go through laparoscopic cholecystectomy or open appendectomy is unknown.

AIM: We conduct this study for comparing the effect of dexamethasone administration with normal saline and with metoclopramide for reducing these undesirable effects.

DESIGN: This was a three-armed, parallel-group, double-blind, and randomized controlled clinical trial.

METHODS: Seventy-two patients of both genders underwent elective surgeries (laparoscopic cholecystectomy or open appendectomy), randomly assigned to three groups: A dexamethasone-treated (8 mg) group (Group 1) ( $n=$ 24), normal saline-treated $(100 \mathrm{ml})$ group (Group 2$)(\mathrm{n}=24)$, and metoclopramide-treated $(10 \mathrm{mg})$ group (Group 3$)$ $(\mathrm{n}=24)$. All nausea, vomiting, and pain episodes were recorded during $24 \mathrm{~h}$ after anesthesia in three time periods: $0-4,4-12$, and $12-24 \mathrm{~h}$ post-anesthesia.

Results: Nausea and vomiting grading scale shows no significant difference when compare dexamethasone (Group 1 ) with normal saline (Group 2), significant difference when compare dexamethasone (Group 1) with metoclopramide (Group 3), and also significant difference when compare normal saline (Group 2) with metoclopramide (Group 3). Group 1 showed a lower pain score $(p<0.01$ and $p<0.0001)$ compared with pain score recorded by patients of Groups 2 and 3, respectively. Besides that, Group 2 also showed a lower pain score $(p<0.0001)$ compared with pain score recorded by Group 3 patients.

CONCLUSION: Dexamethasone has unimportant effect when compare with normal saline, more effectiveness than metoclopramide in reducing PONV. However, dexamethasone more effective in reducing pain when comparing with normal saline and metoclopramide for patients they underwent laparoscopic cholecystectomy or open appendectomy surgery under general anesthesia.
\end{abstract}

\section{Introduction}

Post-operative nausea and vomiting (PONV) commonly occurs following anesthesia and leads to patient dissatisfaction and discomfort. In certain settings, PONV can lead to post-operative complications, especially in a patient that cannot tolerate prominent heart rate or blood pressure, intrathoracic pressure, or central venous pressure.Resources report the frequency of PONV at up to $80 \%$ in high-risk populations and up to $30 \%$ of the general population. Increased medical costs, prolonged hospitalization, and hospital readmission are all common in cases of PONV [1]. Many patients usually rank PONV above pain in terms of distress [2]. Many patients would prefer pain over post-operative nausea or vomiting and would absorb the additional cost to avoid PONV. As the need for ambulatory surgery increases, the prevention of PONV continues to become more important to the system-based approach of anesthesiology [3]. Clinical research displays that PONV is caused principally using inhalational anesthesia and opioid pain reliever. Several risk predictors, including a young age, female sex, absence of smoking, and a history of motion sickness, also rise PONV [4]. Dexamethasone inhibits prostaglandins synthesis, which prepares nerves to other commonly intricate neurotransmitters in emesis regulator [5]. It also may have vital influence in the nucleus tractus solitarius through antagonizing receptors such as $5-\mathrm{HT}_{3}$ and corticosteroid. Many studies show that there is an enhancement of post-discharge recovery quality besides reducing nausea, pain, and fatigue by the administration of $8 \mathrm{mg}$ dexamethasone preoperatively [6]. Weighing the risk-benefit ratio, a new reporting proposes a solitary dose of dexamethasone $4-8 \mathrm{mg}$ is harmless when used prophylactically for PONV [7]. Pain management postoperatively is a chief alarm for clinicians and for 
patients enduring surgery [8]. Post-operative pain not only disturbs the patients operative outcome, health, and fulfillment from medical care but also directly affects the progress of tachycardia, hyperventilation, alveolar ventilation reduction, pain, healing wound poorly, and insomnia, which sequentially may affect the outcomes of operation [9]. Pain is the most public reason of delay patients discharge enduring ambulatory surgery, after drowsiness, and digestive discomfort (i.e. nausea and vomiting) [10]. This study was conducted to evaluate and compare the efficacy of a single dose of dexamethasone, normal saline, and metoclopramide administered intravenously before surgery on PONV and pain in patients undergoing cholecystectomy or appendectomy.

\section{Materials and Methods}

\section{Study population}

This randomized controlled clinical study was carried out at the Salah Aden General Hospital and Al-Iraq private hospital in Salah Aden Governorate, Iraq, from December 2018 to March 2019. Seventy-two patients of both genders undergoing elective surgeries (laparoscopic cholecystectomy or open appendectomy) of 60-120 min duration with an American Society of Anesthesiologists physical status classification system risk of I or II [11] were assigned randomly to three groups: Group 1 involved 24 patients received $8 \mathrm{mg}$ dexamethasone (dissolved in $100 \mathrm{ml}$ isotonic normal saline [0.9\%]) intravenously $30 \mathrm{~min}$ before induction of anesthesia. Group 2 involved 24 patients received $100 \mathrm{ml}$ isotonic normal saline (0.9\%) intravenously 30 min before induction of anesthesia. Group 3 involved 24 patients received $10 \mathrm{mg}$ metoclopramide (dissolved in $100 \mathrm{ml}$ isotonic normal saline [0.9\%]) intravenously 30 minutes before induction of anesthesia. Criteria of exclusion involved history of increased blood pressure, diabetes mellitus, renal, hepatic, or cardiovascular diseases; respiratory diseases; hematologic or digestive tract disorders, or both; hypersensitivity of drugs used in this study; motion sickness or vertigo; former post-operative emesis; pregnant, breastfeeding, or menstruating women; and patient administered antiemetic and analgesic medications within $24 \mathrm{~h}$ previous surgery.

\section{Anesthetic procedure}

Totally, procedures were made under the alike team of anesthesiologists and surgeons. Patients should be not eating for $8 \mathrm{~h}$ before surgery, and no one was pre-medicated. In the operating room, standard five leads electrocardiography, noninvasive blood pressure, and pulse oximetry were attached and baseline hemodynamic parameters were monitored. Anesthesia for patients was induced with propofol (1.5-2.5 mg/kg) (IV bolus dose) followed by IV injection of muscle relaxant of suxamethonium $(1.5-2.0 \mathrm{mg} / \mathrm{kg})$ and anesthesia was maintained with sevoflurane inspiration at $0.5-3 \%$ concentration after tracheal intubation. All patients were mechanically ventilated with $\mathrm{O}_{2}$ /air $(50 / 50 \%), 4 \mathrm{~L} / \mathrm{min}$. The maintenance sevoflurane dose was modified for hemodynamic stability. All over surgery, hydration was kept with an infusion of isotonic solution at a speed of $3 \mathrm{~mL} / \mathrm{kg}-5 \mathrm{~mL} / \mathrm{kg}$. All anesthetic maintenance agents were ended during the last surgical suture. Manually ventilated lungs with $100 \%$ oxygen (4 L/min) up to spontaneous respiration were attained. Neostigmine $(0.03 \mathrm{mg} / \mathrm{kg})$ and atropine $(0.02 \mathrm{mg} / \mathrm{kg})$ were used for antagonize the residual muscle relaxation, and the patients were appropriately extubated. No opioid was given at end of surgery and in post-anesthesia care unit. All patients were removed to post-operative recovery and remonitored after extubation. Patients remained for the evaluation of potential post-operative complications and recovery for at least $1 \mathrm{~h}$.

\section{Data collection}

The primary end point of this study was the total PONV rate up to $24 \mathrm{~h}$ post-anesthesia. The secondary end point was incidence of nausea, incidence of vomiting, and severity of nausea for 24 $\mathrm{h}$ post-anesthesia. All episodes of nausea, vomiting, and pain (whether in the care unit or in the general ward) were recorded during $24 \mathrm{~h}$ after anesthesia in three time periods: $0-4,4-12$, and 12-24 $\mathrm{h}$ postanesthesia and the grade of PONV episodes was scored according to Common Terminology Criteria for Adverse Events version 3.0 using the nauseavomiting grading scale, while pain was scored using visual pain scale after $24 \mathrm{~h}$ of anesthesia [12]. Additional antiemetic (10 mg metoclopramide) was administered intravenously when the nausea and vomiting grading score was $\geq 3$, and additional paracetamol $15 \mathrm{mg} / \mathrm{kg}$ was given intravenously when pain score $\geq 8$. All observations were made by the same trained nurses when the symptoms appeared. Nausea, vomiting, and pain were assessed by the same anesthetist by questioning the patient after recovery from anesthesia. Neither health-care providers (physicians and nurses) nor participants are aware of the time of received medications because the third party blinded the containers and left the fluid containing medication unlabeled (just with coded numbers), so the medications are anonymous for both health-care providers and participants (patients).

\section{Ethical approval}

Approval of the study procedures was obtained from the Ethical Committee of Tikrit University, Iraq, under number of 1085, and consent was obtained 
from all patients after explaining the risk involved and benefits of the study in their own language.

\section{Statistical analysis}

Statistical calculations done using the SPSS (version 21), study parameters were expressed as mean \pm standard deviation. Chi-square test was used for comparisons of discrete variables of the study groups, while continuous variable (parametric values) was evaluated with the one-way ANOVA test and independent two samples t-test. $\mathrm{p}<0.05$ was considered statistically significant.

\section{Results}

\section{groups}

\section{Demographic variables of the study}

Seventy-two patients were enrolled in the study, 24 in each group, 12 underwent appendectomy, and the other 12 underwent cholecystectomy. Insignificant

Table 1: Demographic data of the study groups.

\begin{tabular}{|c|c|c|c|c|}
\hline Parameter & Group 1 & Group 2 & Group 3 & p value \\
\hline Age (years) & $31.12 \pm 13.22$ & $28.33 \pm 11.94$ & $36.25 \pm 13.80$ & $0.11^{\mathrm{a}}$ \\
\hline Weight $(\mathrm{kg})$ & $69.21 \pm 18.29$ & $65.58 \pm 19.73$ & $69.95 \pm 11.17$ & $0.49^{\mathrm{a}}$ \\
\hline Height $(\mathrm{cm})$ & $158.54 \pm 15.15$ & $161.62 \pm 18.52$ & $163.83 \pm 8.53$ & $0.45^{\mathrm{a}}$ \\
\hline BMI $\left(\mathrm{kg} / \mathrm{m}^{2}\right)$ & $27.27 \pm 5.77$ & $24.49 \pm 4.2$ & $26.02 \pm 3.54$ & $0.12^{\mathrm{a}}$ \\
\hline \multicolumn{5}{|c|}{ Gender, n (\%) } \\
\hline Male & $10(41.66 \%)$ & $7(29.16 \%)$ & $8(33.33 \%)$ & \multirow[t]{2}{*}{$0.65^{\mathrm{b}}$} \\
\hline Female & $14(58.33 \%)$ & $17(70.83 \%)$ & $16(66.66 \%)$ & \\
\hline \multicolumn{5}{|c|}{ Smokers, n (\%) } \\
\hline Yes & $2(8.34 \%)$ & $5(20.84 \%)$ & $6(25 \%)$ & \multirow[t]{2}{*}{$0.29^{b}$} \\
\hline No & $22(91.66 \%)$ & $19(79.16 \%)$ & $18(75 \%)$ & \\
\hline
\end{tabular}

difference was found between the study groups in terms of demographic data (age, weight, height, body mass index [BMI], gender distribution, and smoking status), as shown in Table 1.

\section{Incidence rate of nausea}

Results presented in Figure 1 illustrated the incidence of nausea during the first $24 \mathrm{~h}$ after surgery. The frequency of nausea at 0-4 h interval was $6(25 \%)$ patients in Group 1 and 7 (29.16\%) patients in Group 2, while all the patients in Group 3 suffered from nausea at this interval. The frequency of nausea at 4-12 $\mathrm{h}$ interval was 2 (8.33\%) patients in Group 1 while no patients in Group 2 had an episode of nausea at this interval. However, 4 (16.66\%) patients in Group 3 had an episode of nausea at this interval. No patients in all study groups had experience nausea during the third interval of $12-24 \mathrm{~h}$.

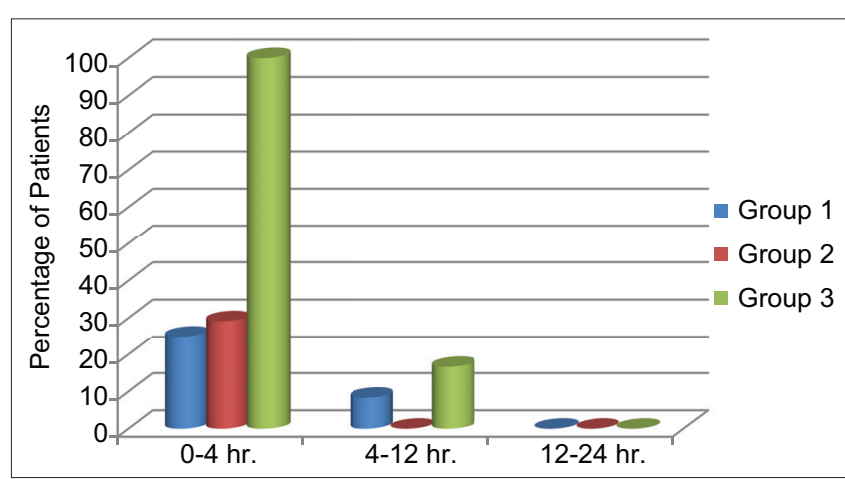

Figure 1: Incidence rate of nausea during the first $24 \mathrm{~h}$ after operation. Group 1: Patient received dexamethasone $(8 \mathrm{mg})(n=24)$, Group 2 Patient received normal saline $(100 \mathrm{ml})(n=24)$, and Group 3: Patient received metoclopramide $(10 \mathrm{mg})(n=24)$

\section{Incidence rate of vomiting}

Results presented in Figure 2 illustrated the incidence of vomiting during the first $24 \mathrm{~h}$ after surgery. The occurrence of vomiting at $0-4 \mathrm{~h}$ interval was seen in $2(8.33 \%)$ patients in Group 2 and in $16(66.66 \%)$ patients in Group 3, while none of the patients in Group 1 had a vomiting episode at this interval. The occurrence of vomiting at 4-12 $\mathrm{h}$ interval was seen in only $1(4.16 \%)$ patient in Group 1 while no patients in Groups 2 and 3 had an episode of vomiting at this interval. No patients in all study groups had experience vomiting during the third interval of $12-24 \mathrm{~h}$.

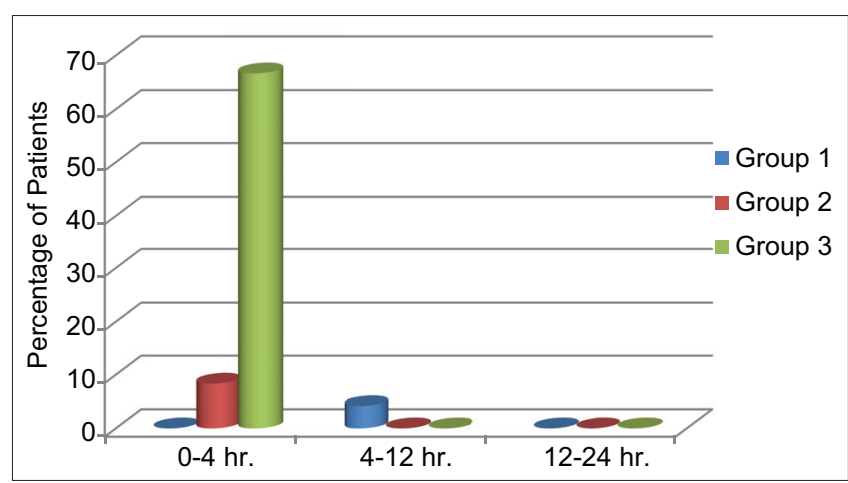

Figure 2: Incidence rate of vomiting during the first $24 h$ after operation. Group 1: Patient received dexamethasone $(8 \mathrm{mg})(n=24)$, Group 2: Patient received normal saline $(100 \mathrm{ml})(n=24)$, and Group 3: Patient received metoclopramide $(10 \mathrm{mg})(n=24)$

\section{Nausea and vomiting grading}

Figure 3 demonstrates the nausea grading according to Common Terminology Criteria for Adverse Events version 3.0. In Group 1, 15 (62.5\%) patients did not have an episode of nausea during the first 24 h after surgery and only $6(25 \%)$ patients had Grade 1, $2(8.33 \%)$ patients had Grade 2, and only 1 patient $(4.16 \%)$ classified as having Grade 3 on nausea grading scale. Besides this, 15 (62.5\%) patients in Group 2 had Grade 0 and 9 (37.5\%) patients had Grade 1 only, and no involvement of other grades. However, 4 (16.66\%), $4(16.66 \%)$, and 16 (66.66\%) of patients in Group 3 had 


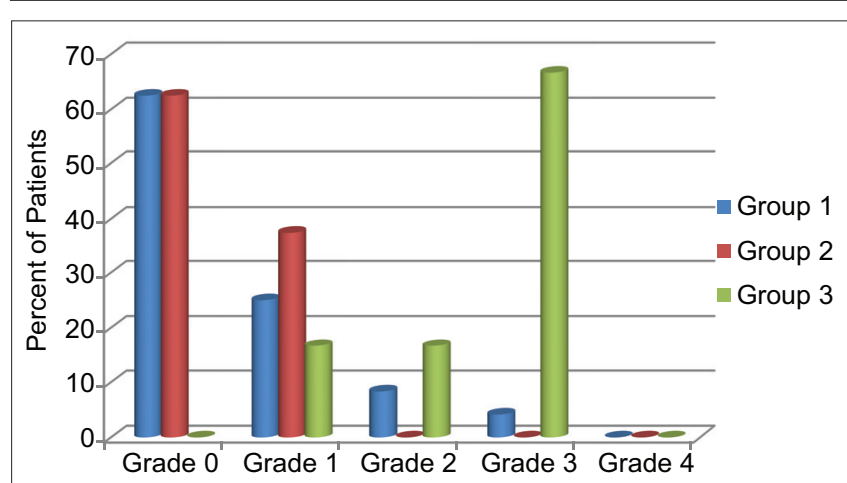

Figure 3: Nausea grading scale. Group 1: Patient received dexamethasone $(8 \mathrm{mg})(n=24)$, Group 2: Patient received normal saline $(100 \mathrm{ml})(n=24)$, and Group 3: Patient received metoclopramide $(10 \mathrm{mg})(n=24)$

Grade 1, Grade 2, and Grade 3, respectively.

Figure 4 demonstrates the vomiting grading in Group 1, 23 (95.83\%) patients had no episode of vomiting during the first $24 \mathrm{~h}$ after surgery, and only $1(4.16 \%)$ patients had Grade 2 . Besides this, $22(91.66 \%)$ patients in Group 2 had Grade 0 and $2(8.33 \%)$ patients had Grade 1, and no involvement of other grades. However, 13 (54.16\%), 2 (8.33\%), $7(29.16 \%)$, and $2(8.33 \%)$ of patients in Group 3 had Grade 1, Grade 2, Grade 3, and Grade 4, respectively.

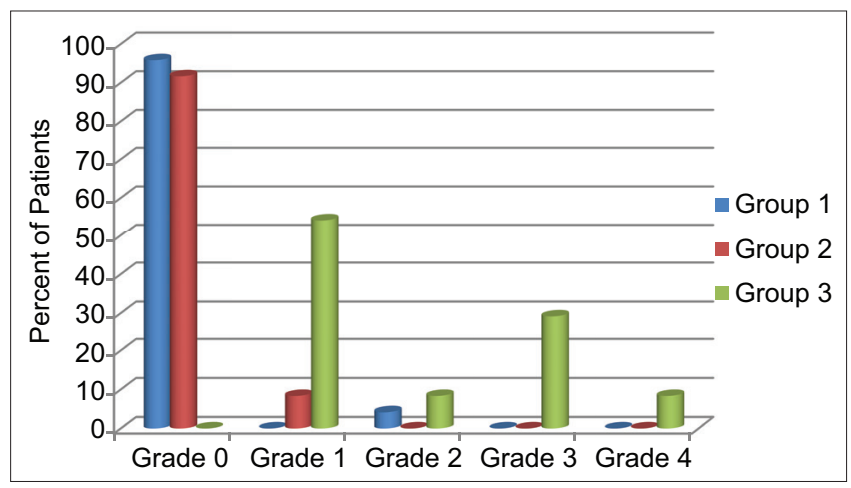

Figure 4: Vomiting grading scale. Group 1: Patient received dexamethasone $(8 \mathrm{mg})(n=24)$, Group 2: Patient received normal saline $(100 \mathrm{ml})(n=24)$, and Group 3: Patient received I.V. metoclopramide $(10 \mathrm{mg})(n=24)$

Nausea and vomiting grading scales in Figures 3 and 4 show no significant difference when compare dexamethasone (Group 1) with normal saline (Group 2) in Grade 0 ( $p>0.999)$, Grade $2(p=0.457)$, Grade $3(p=0.094)$, and Grade $4(p=0.55)$ but significant difference when compare dexamethasone with normal saline (Group 2) in Grade 1 only $(p=0.0003)$ and also significant difference when compare dexamethasone (Group 1) with metoclopramide (Group 3) in Grade 0 (p $<0.0001)$, Grade $1(p<0.0001)$, Grade $2(p<0.0001)$, Grade 3 ( $<<0.0001)$, and Grade 4 ( $<<0.0001)$. In addition, there is a significant difference when compare normal saline (Group 2) with metoclopramide (Group 3) in Grade $0(p<0.0001)$, Grade $1(p<0.0001)$, Grade 2 $(p<0.0001)$, Grade 3 ( $<<0.0001)$, and Grade 4 $(p<0.02)$.

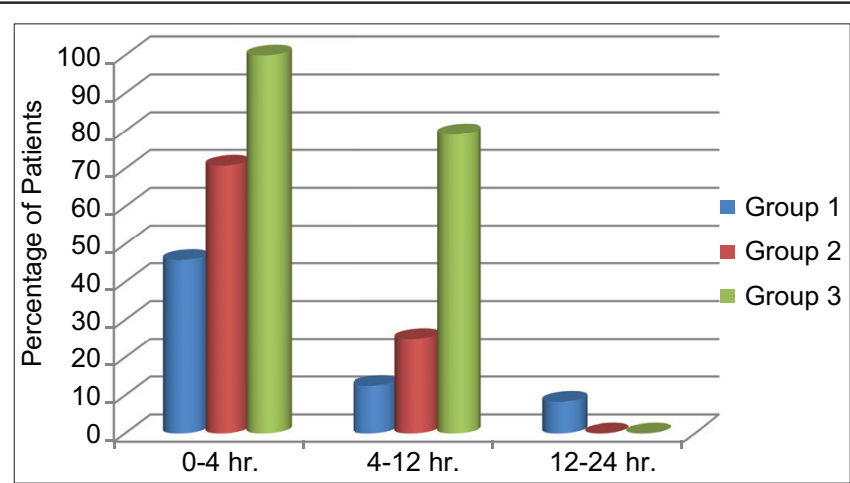

Figure 5: Incidence rate of pain during the first $24 \mathrm{~h}$ after operation Group 1: Patient received dexamethasone $(8 \mathrm{mg})(n=24)$, Group 2 : Patient received normal saline $(100 \mathrm{ml})(n=24)$, and Group 3: Patient received metoclopramide $(10 \mathrm{mg})(n=24)$

\section{Incidence rate of pain}

Results presented in Figure 5 illustrated the incidence of pain during the first $24 \mathrm{~h}$ after surgery. The incidence of pain at $0-4 \mathrm{~h}$ interval was recorded in 11 (45.83\%) patients in Group 1 and $17(70.83 \%)$ patients in Group 2, while all patients in Group 3 had pain at this interval. The incidence of pain at $4-12 \mathrm{~h}$ interval was recorded in $3(12.5 \%)$ patients in Group 1, $6(25 \%)$ patients in Group 2, and $19(79.16 \%)$ patients in Group 3, respectively. Only $2(8.33 \%)$ patients in Group 1 had pain during the third interval of $12-24 \mathrm{~h}$, while no patients in Groups 2 and 3 had experience pain during the third interval of $12-24 \mathrm{~h}$.

\section{Severity of pain}

As illustrated in Table 2, significant differences $(p<0.0001)$ in pain score were observed in this study and patients in Group 1 showed the lowest pain score while patients of Group 3 recorded the highest score. In addition, patients in Group 1 showed a lower pain score $(p<0.01$ and $p<0.0001)$ compared with pain score

Table 2: Pain scores of the study groups. Data expressed as mean $\pm S D$

\begin{tabular}{lllll}
\hline Parameter & Group 1 & Group 2 & Group 3 & p value \\
\hline Pain score & $2.25 \pm 2.131^{\mathrm{a}, \mathrm{b}}$ & $3.916 \pm 2.41^{\mathrm{b}}$ & $7.333 \pm 1.203$ & $<0.0001^{{ }^{*}}$ \\
\hline "One-way ANOVA. $^{\text {aS Significant as compare }}$ with Group 2 (independent two samples t-test). ${ }^{\text {SSignificant as }}$
\end{tabular}
compare with Group 3 (independent two samples t-test).

recorded by patients of Groups 2 and 3, respectively. Besides that, patients in Group 2 also showed a lower pain score $(p<0.0001)$ compared with pain score recorded by patients of Group 3.

\section{Discussion}

In this study, patient demographics, type of surgical procedure, and anesthetic administered were 
similar between groups. In addition, patients with a history of motion sickness or previous post-operative emesis had been excluded from the study; hence, the difference in incidence of PONV between groups was likely attributable to variation in antiemetic drugs. A major finding of this study was dexamethasone $(8 \mathrm{mg})$ has the same effect to the normal saline $(100 \mathrm{ml})$ in lowering the incidence and severity of PONV, but more effective than metoclopramide. However, dexamethasone more effective in reducing pain and less frequently needed analgesics postoperatively compared to normal saline and metoclopramide-treated groups. The mode of action of dexamethasone was still not understood, however, could be attributed to the central inhibition of prostaglandin synthesis, changes in the permeability of the blood-cerebrospinal fluid barrier to serum protein, and/or a decrease in serotonin turnover in the central nervous system [10], dexamethasone also reduces inflammation at the operative site, then reducing the release of inflammatory mediators into the circulation [13]. This is also believed to possibly lead to less stimulation of the vomiting center in the brain. Dexamethasone inhibits the inflammatory response by blocking factors such as bradykinin, prostaglandin, and leukotrienes, which result in a decreased level of inflammation and reduction of the signs and symptoms including pain [14]. A study by Emami et al. suggested that pre-operative dexamethasone $(8 \mathrm{mg})$ reduces the incidence of PONV, pain, and fatigue after laparoscopic cholecystectomy and concluded that the employed regimen is safe and without apparent side effects [15]. Fujii and Nakayama found that dexamethasone (8 $\mathrm{mg}$ ) is effective in reducing the rate of PONV and analgesic requirements in adult Japanese patients undergoing middle ear surgery [16]. Cho et al. proposed that prophylactic administration of 2.5-5 mg dexamethasone can reduce the frequency of PONV, lower visual analog pain scores, facilitate recovery to home readiness, and improve satisfaction in outpatients undergoing anorectal surgery [17]. Talebpour et al. concluded that dexamethasone-promethazine was more effective in reducing PONV and pain than metoclopramidepromethazine combination in patient undergoing laparoscopic gastric placation [18]. Ahsan et al. found a combination of ondansetron with dexamethasone more efficacious than ondansetron alone in preventing PONV after laparoscopic cholecystectomy [19]. Furthermore, a systematic review and meta-analysis of randomized controlled trials investigated by Fan et al. concluded that dexamethasone not only reduces post-operative pain scores and post-operative opioids consumption within $48 \mathrm{~h}$ but also reduces post-operative vomiting and effectively reduces length of stay [20]. The above result agrees with our result where dexamethasone reduces the pain incidence postoperatively but not in agreement with our findings about PONV. Ismail et al., [21] in one study, suggested that patients undergoing laparoscopic cholecystectomy treated with pre-induction dexamethasone $(5 \mathrm{mg})$ plus ringer solution have less incidence of PONV and pain during the first $24 \mathrm{~h}$ than dexamethasone (5 $\mathrm{mg})$ alone. Hence, this outcome strengthens our results about dexamethasone effect on PONV. Wang et al. showed that the incidence of rescue analgesia in the dexamethasone group was lower than in placebo group [22]. Hence, this consequence strengthens our results about pain prophylaxis effect of dexamethasone administration. Metoclopramide is a $\mathrm{D}_{2}$-receptor antagonist and blocks $\mathrm{H}_{1}$ and $5-\mathrm{HT}_{3}$ receptors also. It boosts 5- $\mathrm{HT}_{4}$ receptors and upper gastrointestinal tract motility to stimulate gastric emptying devoid of affecting gastric, biliary, and pancreatic secretion [23]. FDA has been approved metoclopramide exactly to treat nausea and vomiting in patients with gastroesophageal reflux disease or gastroparesis of diabetic by increasing gastric motility. It is also used for controlling nausea and vomiting in chemotherapy patients. In addition, metoclopramide prophylactically administered to inhibit nausea and vomiting in post-operative patients [6]. Our study reveals metoclopramide less effective than dexamethasone and normal saline in reducing nausea incidence, this finding comes in agreement with Kashifard et al. that found ondansetron more/effective than metoclopramide in reducing nausea incidence. Furthermore, Isazadehfar et al. study shows that ondansetron has more effect than metoclopramide in reducing nausea incidence after laparoscopic cholecystectomy [24].

\section{Conclusion}

Single pre-operative injection of dexamethasone $(8 \mathrm{mg})$ was more efficacious in reducing pain score than normal saline $(100 \mathrm{ml})$ and metoclopramide, additionally, has more effect in decreasing PONV incidence when compare to the metoclopramide in patients, undergoing surgery with general anesthesia.

\section{References}

1. Wu M, Yang L, Zeng X, Wang T, Jia A, Zuo Y, et al. Safety and feasibility of early oral hydration in the postanesthesia care unit after laparoscopic cholecystectomy: A prospective, randomized, and controlled study. J Perianesth Nurs. 2019;34(2):425-30. https://doi.org/10.1016/j.jopan.2018.06.093

PMid:30340960

2. Kumar A, Solanki SL, Gangakhedkar GR, Shylasree TS Sharma KS. Comparison of palonosetron and dexamethasone with ondansetron and dexamethasone for postoperative nausea and vomiting in postchemotherapy ovarian cancer surgeries requiring opioid-based patient-controlled analgesia: A randomised, double-blind, active controlled study. Indian J Anaesth. 2018;62(10):773-9. https://doi.org/10.4103/ija. 
ija_437_18

PMid:30443060

3. Aubrun F, Ecoffey C, Benhamou D, Jouffroy L, Diemunsch P, Skaare $\mathrm{K}$, et al. Perioperative pain and post-operative nausea and vomiting (PONV) management after day-case surgery: The SFAR-OPERA national study. Anaesth Crit Care Pain Med. 2019;38(3):223-9. https://doi.org/10.1016/j.accpm.2018.08.004 PMid:30339892

4. Horn CC, Wallisch WJ, Homanics GE, Williams JP. Pathophysiological and neurochemical mechanisms of postoperative nausea and vomiting. Eur J Pharmacol. 2014;722:55-66. https://doi.org/10.1016/j.ejphar.2013.10.037 PMid:24495419

5. Chu CC, Hsing $\mathrm{CH}$, Shieh JP, Chien CC, Ho CM, Wang JJ. The cellular mechanisms of the antiemetic action of dexamethasone and related glucocorticoids against vomiting. Eur J Pharmacol. 2014;722:48-54. https://doi.org/10.1016/j.ejphar.2013.10.008 PMid:24184695

6. Shaikh SI, Nagarekha D, Hegade G, Marutheesh M. Postoperative nausea and vomiting: A simple yet complex problem. Anesth Essays Res. 2016;10(3):388-96. https://doi. org/10.4103/0259-1162.179310 PMid:27746521

7. Ali Khan S, McDonagh DL, Gan TJ. Wound complications with dexamethasone for postoperative nausea and vomiting prophylaxis: A moot point? Anesth Analg. 2013;116(5):966-8. https://doi.org/10.1213/ane.0b013e31828a73de PMid:23606467

8. Sugandarajappa SG, Rashmi NR, Sumitha CS, Chengode S. Comparison of analgesic effect of intra-articular buprenorphine and morphine following arthroscopic surgery of knee. J Evol Med Dent Sci. 2016;5:4175-81. https://doi.org/10.14260/ jemds/2016/953

9. Shoar S, Esmaeili S, Safari S. Pain management after surgery:A brief review. Anesth Pain Med. 2012;1(3):184-6. https://doi.org/10.5812/kowsar.22287523.3443 PMid:24904790

10. Jafra A, Mitra S. Pain relief after ambulatory surgery: Progress over the last decade. Saudi J Anaesth. 2018;12(4):618-25. PMid:30429746

11. Kupeli E, Er Dedekarginoglu B, Ulubay G, Oner Eyuboglu F, Haberal M. American society of anesthesiologists classification versus ARISCAT risk index: Predicting pulmonary complications following renal transplant. Exp Clin Transplant. 2017;15(Suppl 1):208-13. https://doi.org/10.6002/ect. mesot2014.p183

PMid:28260470

12. Hawker GA, Mian S, Kendzerska T, French M. Measures of adult pain: Visual Analog Scale for Pain (VAS pain), Numeric Rating Scale For Pain (NRS Pain), McGill Pain Questionnaire (MPQ), Short-Form McGill Pain Questionnaire (SF-MPQ), Chronic Pain Grade Scale (CPGS), Short Form-36 Bodily Pain Scale (SF-36 BPS), and Measure of Intermittent and Constant Osteoarthritis Pain (ICOAP). Arthritis Care Res (Hoboken). 2011;63 (Suppl 11):S240-52. https://doi.org/10.1002/acr.20543 PMid:22588748

13. Barden A, Phillips M, Hill LM, Fletcher EM, Mas E, Loh PS, et al. Antiemetic doses of dexamethasone and their effects on immune cell populations and plasma mediators of inflammation resolution in healthy volunteers. Prostaglandins Leukot Essent Fatty Acids. 2018;139:31-9. https://doi.org/10.1016/j. plefa.2018.11.004

PMid:30471772

14. Tolska HK, Hamunen K, Takala A, Kontinen VK. Systematic review of analgesics and dexamethasone for post-tonsillectomy pain in adults. Br J Anaesth. 2019;123(2):e397-e411. https://doi. org/10.1016/j.bja.2019.04.063

PMid:31221427

15. Emami H, Nikbakhsh N, Nassab BH, Khafri S, Darzi AA. Efficacy of single-dose of dexamethasone in reduction of pain, nausea and vomiting after laparoscopic cholecystectomy-a randomised controlled trial. J Evol Med Dent Sci. 2018;7:3825-9. https://doi. org/10.14260/jemds/2018/858

16. Fujii $Y$, Nakayama M. Dexamethasone for the reduction of postoperative nausea and vomiting and analgesic requirements after middle ear surgery in adult Japanese patients. Methods Find Exp Clin Pharmacol. 2009;31(5):337-40. https://doi. org/10.1358/mf.2009.31.5.1380460

PMid:19649341

17. Cho E, Kim DH, Shin S, Kim SH, Oh YJ, Choi YS. Efficacy of palonosetron-dexamethasone combination versus palonosetron alone for preventing nausea and vomiting related to opioidbased analgesia: A prospective, randomized, double-blind trial. Int J Med Sci. 2018;15(10):961-8. https://doi.org/10.7150/ ijms.24230

PMid:30013436

18. Talebpour M, Ghiasnejad Omrani N, Imani F, Shariat Moharari R, Pourfakhr P, Khajavi MR. Comparison effect of promethazine/ dexamethasone and metoclopramide/dexamethasone on postoperative nausea and vomiting after laparascopic gastric placation: A randomized clinical trial. Anesth Pain Med. 2017;7(4):e57810. https://doi.org/10.5812/aapm.57810 PMid:29226110

19. Ahsan K, Abbas N, Naqvi SM, Murtaza G, Tariq S. Comparison of efficacy of ondansetron and dexamethasone combination and ondansetron alone in preventing postoperative nausea and vomiting after laparoscopic cholecystectomy. J Pak Med Assoc. 2014;64(3):242-6. https:// doi.org/10.1111/j.1365-2044.2008.05860.x PMid:24864592

20. Fan $Z R$, Ma J, Ma $X L$, Wang $Y$, Sun $L$, Wang $Y$, et al The efficacy of dexamethasone on pain and recovery after total hip arthroplasty: A systematic review and meta-analysis of randomized controlled trials. Medicine (Baltimore). 2018;97(13):e0100. https://doi.org/10.1097/ md.0000000000010100

PMid:29595631

21. Ismail EA, Bakri MH, Abd-Elshafy SK. Dexamethasone alone versus in combination with intra-operative super-hydration for postoperative nausea and vomiting prophylaxis in female patients undergoing laparoscopic cholecystectomy: A randomized clinical trial. Korean J Anesthesiol. 2017;70(5):535-41. https:// doi.org/10.4097/kjae.2017.70.5.535

PMid:29046773

22. Wang B, He KH, Jiang MB, Liu C, Min S. Effect of prophylactic dexamethasone on nausea and vomiting after laparoscopic gynecological operation: Meta-analysis. In: Database of Abstracts of Reviews of Effects (DARE): Quality-assessed Reviews. United Kingdom: Centre for Reviews and Dissemination; 2011.

23. Goineau S, Guillaume P, Castagné V. Comparison of the effects of clonidine, loperamide and metoclopramide in two models of gastric emptying in the rat. Fundam Clin Pharmacol. 2015;29(1):86-94. https://doi.org/10.1111/fcp.12086 PMid:24920467

24. Isazadehfar K, EntezariasI M, Shahbazzadegan B, Nourani Z, Shafaee Y. The comparative study of ondansetron and metoclopramide effects in reducing nausea and vomiting after laparoscopic cholecystectomy. Acta Med Iran. 2017;55(4):254-8. PMid:28532137 